\title{
No change in the consumption of thyroid hormones after starting low dose naltrexone (LDN): a quasi-experimental before-after study
}

\author{
Guttorm Raknes ${ }^{1,2}$ (D) and Lars Småbrekke ${ }^{3^{*}}$ (1)
}

\begin{abstract}
Background: Low dose naltrexone (LDN) is reported to have beneficial effects in several autoimmune diseases. The purpose of this study was to examine whether starting LDN was followed by changes in the dispensing of thyroid hormones to patients with hypothyroidism.

Methods: We performed a quasi-experimental before-after study based on the Norwegian Prescription Database. Study participants were identified by using reimbursement codes for hypothyroidism. Cumulative dispensed Defined Daily Doses and the number of users of triiodothyronine (T3) and levothyroxine (LT4) 1 year before and after the first LDN prescription was compared in three groups based on LDN exposure.

Results: We identified 898 patients that met the inclusion criteria. There was no association between starting LDN and the subsequent dispensing of thyroid hormones. If anything, there was a tendency towards increasing LT4 consumption with increasing LDN exposure.
\end{abstract}

Conclusion: The results of this study do not support claims of efficacy of LDN in hypothyroidism.

Keywords: Endocrinology, Hypothyroidism, Naltrexone, Levothyroxine, Triiodohyronine, Pharmacoepidemiology

\section{Background}

The opioid antagonist naltrexone in low doses (typically < $5 \mathrm{mg} /$ day) is being used off-label against several autoimmune diseases. In a recent review, the authors claim that low dose naltrexone (LDN) has beneficial immunomodulatory effects by acting on the opioid growth factor receptor (OGFr) or as a direct immunomodulating agent, by elevating endogenous opioids, or by affecting cytokine production [1].

A few small randomized clinical trials show promising results in inflammatory bowel disease, multiple sclerosis

\footnotetext{
* Correspondence: lars.smabrekke@uit.no

${ }^{3}$ Department of Pharmacy, Faculty of Health Sciences, UiT - The arctic university of Norway, Troms $\varnothing$, Norway

Full list of author information is available at the end of the article
}

and chronic pain conditions [1]. Although no studies in thyroid disease have been published, LDN has been proposed as an alternative add-on to regular hypothyroid therapy. Some patients report astounding improvements [2], and there are patients and doctors who claim that LDN may be beneficial in autoimmune thyroid disease, but definitive evidence is lacking [3].

Decades of high dose naltrexone in the treatment of opioid and alcohol addiction indicate that LDN has an excellent safety profile [4], and with increasing awareness among patients, it is highly likely that endocrinologists increasingly will have requests to prescribe LDN.

In 2013, the number of users of LDN in Norway increased from almost zero to $0.3 \%$ of the population within few months following a TV documentary [5]. This surge 
in LDN use could be considered a natural experiment that make quasi-experimental pharmacoepidemiological studies possible. We seized the opportunity to examine whether there were changes in the dispensing of thyroid hormones in selected patients following the initiation of LDN therapy. If LDN is actually efficacious in hypothyroidism, it is plausible that it would result in changes in the use of triiodothyronine (T3) and/or levothyroxine (LT4).

\section{Methods}

This was a controlled before-after study based on data from the Norwegian Prescription Database (NorPD). The NorPD contains information on prescriptions dispensed to all Norwegian residents [6]. For a fee, NorPD used reimbursement codes for hypothyroidism (International Classification of Disease (ICD-10) code E03 and International Classification of Primary Care (ICPC-2) code T86) to identify patients in the database according to our specifications. We received an encrypted data file allowing us to follow individual patients without knowing their identity. The database does not contain any other clinical information related to thyroid disease than the prescribing of thyroid hormones. To increase specificity, we only included patients that collected at least two prescriptions containing reimbursement codes for hypothyroidism in 2009 and 2010, and had collected $\geq 1$ LDN prescriptions in 2013. We defined the first prescription in 2013 as index data, and stratified patients in three groups according to LDN exposure in the 2 years after index date: $\mathrm{LDN} \times 1$ (controls, collected LDN once), LDN $\times 2-3$ (collected LDN twice or thrice) and LDN $\times 4+$ (persistent users, collected LDN $>3$ times). We have previously used the same stratification in other studies [7-9].

Outcomes were differences between the cumulative collected amounts of Defined Daily Doses (DDDs) and the number of users of levothyroxine (LT4) and triiodothyronine (T3). One DDD LT4 equals $150 \mu \mathrm{g}$, and one DDD triiodothyroxine is $60 \mu \mathrm{g}$. We calculated the difference for each patient by subtracting the number of collected DDDs of T3 and LT4 year following the first LDN prescription from the number of DDDs in the year preceding the first LDN prescription. All index dates were in 2013, and the total observation time was 2 years for all participants. The first observation date was theoretically January 1, 2012, and the last observation date was December 31, 2014.

\section{Statistical methods}

The study size depended on the number of patients in NorPD meeting our inclusion criteria. We used SPSS 25 and Excel 2013 for data management and statistical analysis, and analyzed all data on individual level. We used a pairwise two-sided $t$-test to investigate the mean changes in the sum of the DDDs per patient in each group for all examined medicines. In addition, we calculated 95\% confidence intervals (CI) for the difference of means. Change in the number of users was expressed as the proportion of each group, together with the $95 \% \mathrm{CI}$ for the difference of the proportion (in \% points) [10]. Difference-in-difference of DDDs and the proportion of users (in \% points) with 95\% CI were calculated.

In addition, we conducted an ANCOVA to compare differences in T3 and LT4 dispensing before and after index date while adjusting for sex, age in 2013, and the number of prescriptions (all prescription medicines) collected 1 year before index date.

\section{Results}

We identified 898 patients who met the inclusion criteria. Baseline data are given in Table 1 . There were negligible differences between groups in age, proportion females and the cumulative number of prescriptions of all medicines per person 1 year before index date.

Differences in DDD are shown in Table 2. There were no T3 or LT4 DDD differences between groups before or after starting LDN, or within groups before-after. The differencein-difference between LDN $\times 1$ and $\mathrm{LDN} \times 4+$ for LT4 was not significant (6.2 DDD, 95\% CI -11.3 to $23.7, p=0.313$ ), but the dispensed cumulative DDD in LDN $\times 4+$ LT4 dispensing after was almost significantly larger after starting LDN (19.8 DDD, 95\% CI -0.1 to 23.7, $p=0.060$ ).

There were no differences in the number of users of neither T3 nor LT4, except for a $2.0 \%$ points borderline significant reduction in the number of LT4 users in the LDN $\times 2-3$ group (Table 3 ). There was no difference-indifference in number of users of LT4 between LDN $\times 1$ and $\mathrm{LDN} \times 4+(1.2 \%$ points, $95 \% \mathrm{CI}-1,8$ to $4,1, p=$ $0.441)$ or between LDN $\times 2-3$ and $\mathrm{LDN} \times 4+(2.0 \%$ points, $95 \% \mathrm{CI}-0.5$ to $4.5, p=0.113)$. For the number of T3 users, there was no difference-in-difference between groups, for example $\mathrm{LDN} \times 1$ vs. $\mathrm{LDN} \times 4+: 2.4 \%$ points, $95 \% \mathrm{CI}-0.9$ to $5.8, p=0.151$ ).

The results of the ANCOVA analyses are given in Additional file 1. Levene's test and normality checks were carried out and the assumptions met. When adjusting for sex, age and number of prescriptions dispensed before index date in the model, no differences between LDN groups in the change of dispensing was observed

Table 1 Baseline data

\begin{tabular}{|c|c|c|c|c|c|c|}
\hline \multirow[b]{2}{*}{ N (\%) } & \multicolumn{2}{|c|}{$\operatorname{LDN} \times 1$} & \multicolumn{2}{|c|}{$\begin{array}{l}\operatorname{LDN} \times 2- \\
3\end{array}$} & \multicolumn{2}{|c|}{ LDN $\times 4+$} \\
\hline & 260 & (29.0) & 198 & (22.0) & 440 & (49.0) \\
\hline Female (\%) & 240 & (92.3) & 178 & (89.9) & 415 & (94.3) \\
\hline Age $( \pm S D)$ & 58.0 & $(12.2)$ & 55.7 & (12.4) & 54.7 & (13.0) \\
\hline $\begin{array}{l}\text { Number of prescriptions } \\
\text { before LDN } \\
\text { (all drugs) }( \pm S D)\end{array}$ & 32.1 & (38.3) & 30.8 & (32.6) & 30.8 & (13.4) \\
\hline
\end{tabular}


Table 2 Average cumulative number of DDDs of thyroid hormones dispensed to patients 1 year before and after the first dispense of LDN. Patients stratified based on the number of LDN dispenses: LDN $\times 1(N=260)$, LDN $\times 2-3(N=198)$ and LDN $\times 4+(N=440)$. LDN: Low dose naltrexone. DDD: Defined daily dose

\begin{tabular}{|c|c|c|c|c|c|}
\hline & \multicolumn{2}{|c|}{ Dispensed drugs (DDD) } & \multicolumn{2}{|c|}{ Difference (DDD) } & \multirow[b]{2}{*}{$\mathrm{p}$} \\
\hline & Before & After & Mean & 95\% $\mathrm{Cl}$ difference & \\
\hline \multicolumn{6}{|c|}{ Levothyroxine (LT4) } \\
\hline $\mathrm{LDN} \times 1$ & 225.4 & 223.1 & -2.3 & $(-15.9$ to 11.2$)$ & 0.737 \\
\hline $\mathrm{LDN} \times 2-3$ & 245.9 & 248.9 & 3.0 & $(-15.6$ to 21.5$)$ & 0.754 \\
\hline $\operatorname{LDN} \times 4+$ & 239.0 & 242.9 & 3.9 & $(-7.1$ to 14.9$)$ & 0.490 \\
\hline \multicolumn{6}{|c|}{ Triiodothyronine (T3) } \\
\hline $\mathrm{LDN} \times 1$ & 10.4 & 10.5 & 0.1 & $(-2.8$ to 3.1$)$ & 0.932 \\
\hline $\mathrm{LDN} \times 2-3$ & 8.1 & 5.9 & -2.2 & $(-5.1$ to 0.7$)$ & 0.139 \\
\hline LDN $\times 4+$ & 11.4 & 11.1 & -0.3 & (-2.9 to 2.3$)$ & 0.818 \\
\hline
\end{tabular}

for neither T3 $(\mathrm{F}(2,892)=0.53, p=0.588))$ nor LT4 $(\mathrm{F}$ $(2,892)=0.246, p=0.782))$.

\section{Discussion}

We found no association between starting LDN and changes in the dispensing of thyroid hormones. If anything, there was a tendency towards increasing LT4 consumption with increasing LDN exposure.

There was a reduction in users LT4 in the group with intermediate $\mathrm{LDN}$ exposure $(\mathrm{LDN} \times 2-3)$, but this does not suggest efficacy of LDN in hypothyroidism. There was no significant differencein-difference between groups. Since the persistent LDN users $(\mathrm{LDN} \times 4+)$ had the least reduction in the number of LT4 users, this finding does not fit into a dose-response relationship.

NorPD is a reliable data source that contains almost complete information on all prescribing outside

Table 3 The number of users of thyroid hormones dispensed 1 year before and after the first dispense of LDN. The groups are stratified based on the number of LDN dispenses: LDN $\times 1$ ( $N=$ 260), LDN $\times 2-3(N=198)$ and LDN $\times 4+(N=440)$. LDN: Low dose naltrexone

\begin{tabular}{|c|c|c|c|c|c|c|c|}
\hline & \multicolumn{4}{|c|}{ Number of users } & \multicolumn{3}{|c|}{ Difference } \\
\hline & \multicolumn{2}{|c|}{ Before } & \multicolumn{2}{|c|}{ After } & \multirow[b]{2}{*}{$\%$ points } & \multirow[b]{2}{*}{$95 \% \mathrm{Cl}$} & \multirow[b]{2}{*}{$p$} \\
\hline & $\mathbf{N}$ & $\%$ & $\mathrm{~N}$ & $\%$ & & & \\
\hline \multicolumn{8}{|c|}{ Levothyroxine (LT4) } \\
\hline $\mathrm{LDN} \times 1$ & 243 & (93.5) & 240 & $(92.3)$ & -1.2 & $(-3.7$ to 1.3$)$ & 0.366 \\
\hline $\mathrm{LDN} \times 2-3$ & 191 & $(96.5)$ & 187 & $(94.4)$ & -2.0 & $(-4.0$ to -0.1$)$ & 0.045 \\
\hline $\mathrm{LDN} \times 4+$ & 420 & (95.5) & 420 & $(95.5)$ & 0.0 & $(-1.5$ to 1.5$)$ & 1.000 \\
\hline \multicolumn{8}{|c|}{ Triiodothyronine (T3) } \\
\hline $\mathrm{LDN} \times 1$ & 28 & $(10.8)$ & 24 & $(9.2)$ & -1.5 & $(-4.1$ to 1.1$)$ & 0.248 \\
\hline $\mathrm{LDN} \times 2-3$ & 15 & (7.6) & 11 & (5.6) & -2.0 & $(-5.1$ to 1.1$)$ & 0.206 \\
\hline $\mathrm{LDN} \times 4+$ & 51 & (11.6) & 55 & $(12.5)$ & 0.9 & $(-1.2$ to 3.0$)$ & 0.394 \\
\hline
\end{tabular}

institutions in Norway, and the inclusion criteria probably lead to a representative sample of the LDN using hypothyroidism population. The strict inclusion criteria reduced the risk of accidental misdiagnosis and bias due to patients starting thyroid hormones during the observation period. Register-based studies have important limitations, and among the most important is scarce clinical information. The prescribing of T3and LT4 are only proxies to thyroid function, and we cannot rule out possible beneficial or negative effects of LDN not leading to changes in the dosing of thyroid hormones. In addition, the data did not allow any stratification between different types of hypothyroidism, and it was not possible to adjust for body weight. It is possible that the use of large amounts of thyroid hormones in obese patients could cancel data from leaner patients. We do not believe this was a major source of bias, since the outcome was pairwise differences in prescribing of T3 and LT4, not total cumulative use.

Quasi-experimental studies have limitations due to non-random assignment, and in this study, we did not include a control group that was unexposed to LDN. Bias in the inclusion of patients, temporal factors such as natural course of disease and regression to the mean are other problems associated with before-after studies [11].

The negative findings in this study fit into the mixed results of clinical and pharmacoepidemiological studies on LDN in autoimmune disease $[1,8,9]$.

\section{Conclusions}

The initiation of LDN therapy was not followed by changes in the use of thyroid hormones. The results of this study do not support claims of efficacy of LDN in hypothyroidism. 


\section{Supplementary information}

Supplementary information accompanies this paper at https://doi.org/10. 1186/s12902-020-00630-4.

Additional file 1:. ANCOVA analyses

\section{Abbreviations}

DDD: Defined Daily Dose; ICD: International classification of disease; ICPC: International Classification of Primary Care; LDN: Low dose naltrexone; NorPD: The Norwegian Prescription Database; OGFr: Opioid growth factor receptor; T3: Triiodothyronine; LT4: Levothyroxine

\section{Acknowledgements}

We would like to thank Frode Skjold for preparing the data.

\section{Authors' contributions}

GR: Planned the study, did the statistical analysis, drafted the manuscript. LS: Planned the study, contributed in statistical analysis and in completing the manuscript. All authors have read and approved the manuscript.

\section{Funding}

None.

\section{Availability of data and materials}

Restrictions apply to the availability of data generated or analyzed during this study to preserve patient confidentiality or because they were used under license. The corresponding author will on request detail the restrictions and any conditions under which access to some data may be provided.

Data is available from the Norwegian Prescription Database (NorPD) for researchers who after application meet the criteria for access to prescription data. This includes Ethics Committee evaluation and a fee will be charged. For further details, please see https://www.fhi.no/en/hn/health-registries/ norpd/Access-data-norpd/. We did not have any special privileges accessing the data, we obtained the data through the same application and fee payment process as outlined here. Our approvals do not allow the publication of raw data used in this study. In accordance with NorPD's requirements, we had to delete all original data by 31 December 2018.

\section{Ethics approval and consent to participate}

The Regional Committee for Medical and Health Research Ethics of Northern Norway reviewed the study protocol. Due to the encrypted data, the committee concluded that disclosure was not mandatory. The local privacy ombudsman for research at the University Hospital of Northern Norway approved the project. Consent from individual patients is by law not required for research based on NorPD.

\section{Consent for publication}

Not relevant.

\section{Competing interests}

None.

\section{Author details}

${ }^{1}$ Regional Medicines Information and Pharmacovigilance Centre (RELIS), University Hospital of North Norway, Tromsø, Norway. ${ }^{2}$ Raknes Research, Ulset, Norway. ${ }^{3}$ Department of Pharmacy, Faculty of Health Sciences, UiT The arctic university of Norway, Tromsø, Norway.

Received: 21 February 2020 Accepted: 24 September 2020 Published online: 01 October 2020

\section{References}

1. Li Z, You Y, Griffin N, Feng J, Shan F. Low-dose naltrexone (LDN): a promising treatment in immune-related diseases and cancer therapy. Int Immunopharmacol. 2018;61:178-84. https://doi.org/10.1016/j.intimp.2018.05. 020.

2. Elsegood L. Hypothyroidism. In: LDN Research Trust; 2018. https://www. Idnresearchtrust.org/video-categories/hypothyroidism. Accessed 15 Jan 2020 .
3. McDermott MT. Low-dose naltrexone treatment of Hashimoto's thyroiditis In: McDermott M, editor. Management of Patients with pseudo-endocrine disorders. Cham: Springer; 2019. p. 317-26.

4. Bolton M, Hodkinson A, Boda S, Mould A, Panagioti M, Rhodes S, Riste L, van Marwijk H. Serious adverse events reported in placebo randomised controlled trials of oral naltrexone: a systematic review and meta-analysis. BMC Med. 2019;17:10. https://doi.org/10.1186/s12916-018-1242-0.

5. Raknes G, Småbrekke L. A sudden and unprecedented increase in low dose naltrexone (LDN) prescribing in Norway. Patient and prescriber characteristics, and dispense patterns. A drug utilization cohort study. Pharmacoepidemiol Drug Saf. 2017;26:136-42.

6. Furu K. Establishment of the nationwide Norwegian prescription database (NorPD)-new opportunities for research in pharmacoepidemiology in Norway. Nor J Epidemiol. 2008;18:129-36. https://doi.org/10.5324/nje.v18i2. 23.

7. Raknes G, Småbrekke L. Low-dose naltrexone and opioid consumption: a drug utilization cohort study based on data from the Norwegian prescription database. Pharmacoepidemiol Drug Saf. 2017;26:685-93. https://doi.org/10.1002/pds.4201.

8. Raknes G, Småbrekke L. Low dose naltrexone in multiple sclerosis: effects on medication use. A quasi-experimental study. PLoS One. 2017;12:e0187423. https://doi.org/10.1371/journal.pone.0187423.

9. Raknes G, Simonsen P, Småbrekke L. The effect of low-dose naltrexone on medication in inflammatory bowel disease: a quasi experimental beforeand-after prescription database study. J Crohns Colitis. 2018;12:677-86. https://doi.org/10.1093/ecco-jcc/jjy008.

10. Altman DG. Comparing groups—categorical data. In: Altman DG, editor. Practical Statistics for Medical Research. 1st ed. London: Chapman \& Hall: 1991. p. 234-41.

11. Torgerson DJ, Torgerson CJ. The limitations of before and after designs. In: Torgerson DJ, Torgerson CJ, editors. Designing randomised trials in health, education and the social sciences. London: Palgrave Macmillan UK; 2008. p. 9-16.

\section{Publisher's Note}

Springer Nature remains neutral with regard to jurisdictional claims in published maps and institutional affiliations.
Ready to submit your research? Choose BMC and benefit from:

- fast, convenient online submission

- thorough peer review by experienced researchers in your field

- rapid publication on acceptance

- support for research data, including large and complex data types

- gold Open Access which fosters wider collaboration and increased citations

- maximum visibility for your research: over $100 \mathrm{M}$ website views per year

At $\mathrm{BMC}$, research is always in progress.

Learn more biomedcentral.com/submission 